\title{
Decreased retinol-binding protein 4 in the sera of patients with end-stage renal disease after kidney transplantation
}

\author{
W.X. Zhang ${ }^{1}$, W. Zhou ${ }^{1}$, Z.M. Zhang ${ }^{1}$, Z.Q. Zhang ${ }^{1}$, J.F. He ${ }^{2}$ and B.Y. Shi ${ }^{3}$ \\ ${ }^{1}$ Department of Nephrology, PLA 309th Hospital, Beijing, China \\ ${ }^{2}$ Department of Laboratory Test, PLA 309th Hospital, Beijing, China \\ ${ }^{3}$ PLA Institute of Transplantation, PLA 309th Hospital, Beijing, China
}

Corresponding author: B.Y. Shi

E-mail: bingyishi@yeah.net

Genet. Mol. Res. 13 (4): 8126-8134 (2014)

Received July 29, 2013

Accepted April 2, 2014

Published October 7, 2014

DOI http://dx.doi.org/10.4238/2014.October.7.7

\begin{abstract}
Retinol-binding protein 4 (RBP4) is a novel adipokine that has been associated with insulin resistance and type 2 diabetes. Patients with end-stage renal disease (ESRD) have very high serum RBP4 levels. However, whether successful kidney transplantation alleviates these elevated serum RBP4 levels is unclear. The serum RBP4 levels of 24 ESRD patients were determined before transplantation and at 1 day, 1 week, and 1 month after kidney transplantation. The control group included 22 healthy subjects. Serum RBP4 concentrations were measured using a commercial kit via the immunologic turbidimetric method, and were related to biomarkers for renal and liver function. The serum RBP4 level of ESRD patients before kidney transplantation $(160.8 \pm 29.1 \mathrm{mg} / \mathrm{L})$ was
\end{abstract}


approximately 7-fold higher than that of normal controls $(22.6 \pm 11.0$ $\mathrm{mg} / \mathrm{L} ; \mathrm{P}=0.000$ ). The serum RBP4 level before transplantation was significantly higher than that at 1 day $(65.3 \pm 28.4 \mathrm{mg} / \mathrm{L}), 1$ week $(48.3 \pm 22.9 \mathrm{mg} / \mathrm{L})$, and 1 month after transplantation $(53.1 \pm 25.5$ $\mathrm{mg} / \mathrm{L} ; \mathrm{P}=0.000)$. However, these values were still higher than those of controls $(\mathrm{P}=0.000)$. Univariate regression analysis showed that the percent changes in serum RBP4 concentration before and after kidney transplantation were positively correlated with serum creatinine, blood urea nitrogen, phosphate, and pre-albumin concentrations and negatively correlated with the estimated glomerular filtration rate. The serum RBP4 concentration of patients with ESRD decreased significantly after kidney transplantation; therefore, we found that serum RBP4 concentration was related to renal function.

Key words: End-stage renal disease; Kidney transplantation; Renal function; Retinol-binding protein 4

\section{INTRODUCTION}

Retinol-binding protein 4 (RBP4), a 21-kDa protein, was originally recognized as the specific transport protein for vitamin A (retinol, $\mathrm{ROH}$ ) in circulation, delivering hydrophobic retinol from the liver to target tissues (Smith and Goodman, 1971; Goodman, 1984; Blaner, 1989). However, Yang et al. (2005) recently reported that RBP4 is an adipokine that impairs insulin sensitivity. Circulating RBP4 was found to be elevated in a mouse model for insulin resistance and in patients with obesity and type 2 diabetes (Naylor and Newcomer, 1999; Yang et al., 2005; Graham et al., 2006; Janke et al., 2006). RBP4 knockout mice show improved insulin sensitivity and transgenic RBP4 overexpression, and injecting recombinant RBP4 into normal mice induces insulin resistance (Yang et al., 2005).

RBP4 is primarily produced in the liver and adipose tissues, and it is secreted into the circulation in a ratio of 1:1:1 with ROH (holo-RBP4) and transthyretin (Ronne et al., 1983; Naylor and Newcomer, 1999). The binding with tristetraprolin increases its molecular weight and prevents its filtration and catabolism in the kidney (Vahlquist et al., 1973; Goodman, 1980; Kiernan et al., 2002; Wihler et al., 2005; Yang et al., 2005). After releasing ROH into the target cells, the remaining apo-RBP4 (unbound ROH) is quickly filtered through the glomeruli and reabsorbed into the proximal tubules via the megalin-cubilin receptor complex, and then catabolized (Peterson and Berggard, 1971; Mogielnicki et al., 1971; Raila et al., 2005). Therefore, liver and kidney dysfunctions can interfere with RBP4 homeostasis, and chronic kidney and liver diseases influence RBP4 metabolism by altering RBP4 synthesis and catabolism (Smith and Goodman, 1971; Goodman, 1980; Adoncecchi et al., 1984; Bernard et al., 1988; Jaconi et al., 1995).

Several studies reported that RBP4 is consistently elevated in end-stage renal disease (ESRD) patients, who show 3.5-5 times the normal serum RBP4 concentrations (Farrington et al., 1981; Stewart and Fleming, 1982; Vahlquist et al., 1982; Blumberg et al., 1983). Ziegelmeier et al. (2007) showed that patients undergoing chronic hemodialysis have 4-fold higher mean serum RBP4 levels than control subjects with glomerular filtration rates $>50 \mathrm{~mL} / \mathrm{min}$. 
In addition, serum creatinine independently predicted RBP4 concentrations in multiple regression analyses. These studies suggest that decreased renal filtration significantly affects serum RBP4 concentrations. Thus, improving renal function may decrease serum RBP4 concentrations. In this study, we examined whether improved renal filtration after kidney transplantation affects serum RBP4 concentration.

\section{MATERIAL AND METHODS}

\section{Patients}

Participants were selected from a pool of patients treated for ESRD who underwent renal transplantation at the Institute of Transplantation of PLA 309 Hospital between August 10, 2011 and October 10, 2011. A total of 24 patients were selected (21 males and 3 females), ranging from 16-58 years of age (mean age, $34.1 \pm 11.1$ years). Causes of kidney disease included glomerulonephritis $(\mathrm{N}=20)$, diabetic nephropathy $(\mathrm{N}=3)$, and kidney tuberculosis $(\mathrm{N}=1)$. All patients who participated in this study fulfilled the diagnostic criteria for ESRD and underwent hemodialysis for 6-72 months (mean duration $18.3 \pm 15.1$ months). Before kidney transplantation, patients were taking routine anti-hypertensive drugs, iron, vitamin D metabolites, and calcium, and they were on erythropoietin therapy. After kidney transplantation, patients were treated with steroids, cyclosporine (or tacrolimus), and mycophenolate mophetil. Transplanted kidneys were from 16 deceased donors and from 8 living relatives of the patients. The control group included 22 healthy volunteers (16 males and 6 females) who were 20-50 years of age (mean age, $32.6 \pm 11.9$ years) and were hospital workers who received annual health examinations. The control subjects were healthy based on a general health and life style questionnaire, serum creatinine, hematology, liver enzymes, and other blood biochemistry parameters, as well as blood pressure. This study was conducted in accordance with the Declaration of Helsinki. This study was conducted with approval from the Ethics Committee of PLA 309 Hospital. Written informed consent was obtained from all participants.

\section{Assays}

At 6 am, fasting blood samples were collected from ESRD patients (before kidney transplantation and at 1 day, 1 week, and 1 month after kidney transplantation) and healthy controls. Serum samples were prepared by drawing blood was directly into anticoagulant-free centrifuge tubes, which were incubated at room temperature for 30 min to allow blood clotting, and then centrifuged at $3000 \mathrm{~g}$ for $15 \mathrm{~min}$ at $4^{\circ} \mathrm{C}$. The serum samples obtained (from ESRD patients and healthy controls) were then stored in aliquots at $-80^{\circ} \mathrm{C}$ until the RBP4 assay was performed. The serum RBP4 concentration was determined using a commercially available turbidimetric immunoassay system (Simes-Sikma Corporation, Beijing, China) on a Hitachi 7600-020 automatic analyzer following manufacturer instructions. The estimated glomerular filtration rate (eGFR) was calculated using the method described in the simplified Modification of Diet in Renal Disease study (Levey et al., 2000). Laboratory parameters (Table 1) acquired from medical records were measured using standard laboratory methods in the hospital laboratory. 


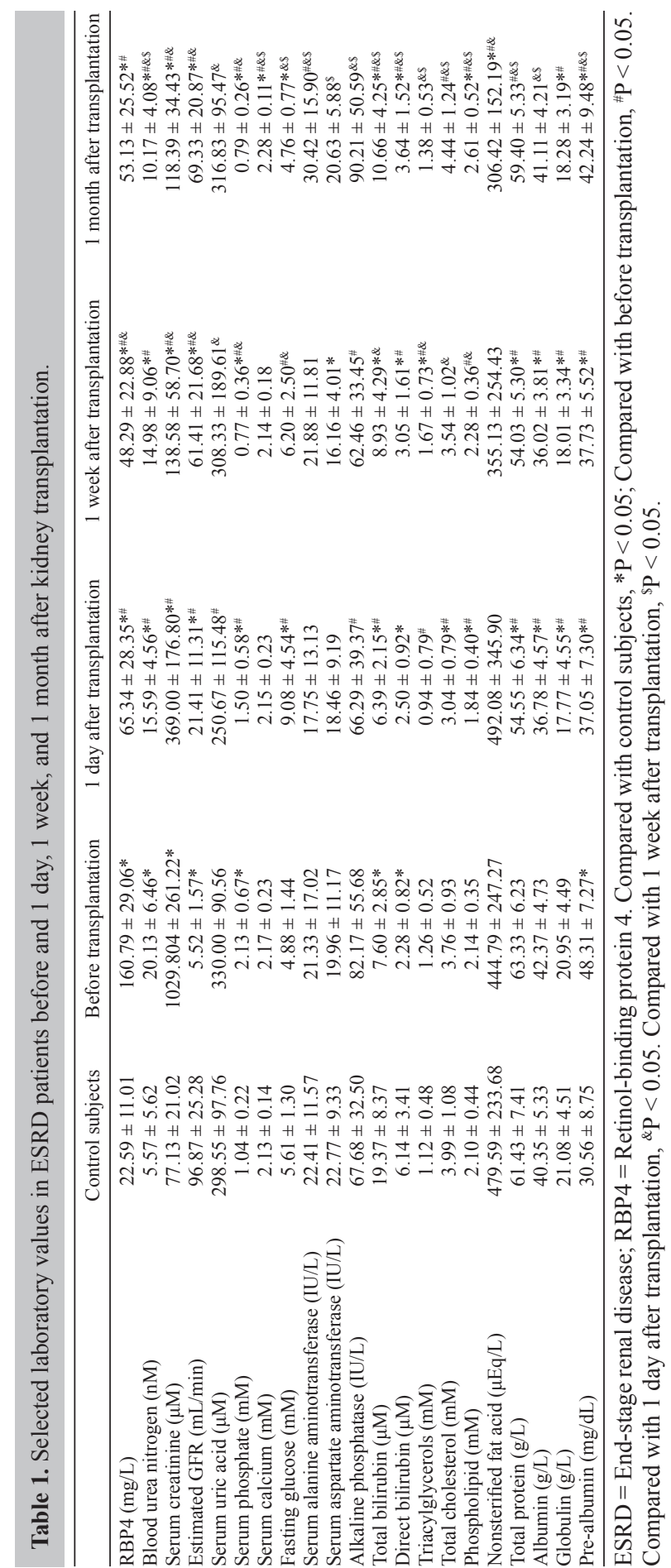




\section{Statistical analysis}

Primary data was collected using the Excel software (Microsoft, Redmond, WA, USA) and statistical analyses were performed using the SPSS software version 13.0 (SPSS, Inc., Chicago, IL, USA). The statistical significance of the differences in patient parameters before and after kidney transplantation was assessed using a paired $t$-test for data that was normally distributed or a nonparametric paired Wilcoxon test for laboratory parameters that were not normally distributed. The statistical significance of differences between patients with ESRD and healthy controls was assessed using a 2-tailed Student $t$-test for normally distributed data or a nonparametric Mann-Whitney test for laboratory parameters that were not normally distributed. Differences showing P $<0.05$ were considered to be statistically significant. Pearson's correlation coefficient was calculated to assess the correlation between the percent change in serum RBP4 concentration and percent change in selected patient parameters before and after kidney transplantation.

\section{RESULTS}

Before kidney transplantation, ESRD patients displayed significant higher (approximately 7-fold) serum RBP4 (Table 1, Figure 1A), lower eGFR (Table 1, Figure 1B), higher serum creatinine (Table 1, Figure 1C), and higher serum pre-albumin (Table 1, Figure 1D) compared with healthy subjects. A significant progressive increase in eGFR (Table 1, Figure 1B) and progressive decrease in serum creatinine (Table 1, Figure 1C) were observed at 1 day, 1 week, and at 1 month after kidney transplantation. Concomitantly, serum RBP4 decreased significantly at 1 day (to approximately 3 -fold of the normal controls), and decreased more at 1 week (to approximately 2 -fold of the normal controls). This level was found to be maintained at 1 month after kidney transplantation (Table 1, Figure 1A). Serum pre-albumin (Table 1, Figure 1D) decreased significantly after kidney transplantation; however, a recovery was observed at 1 month, although the values were below those observed before transplantation.

Correlation analysis showed that percent changes in serum RBP4 were positively correlated with serum creatinine $[1$ day: $\mathrm{r}=0.685, \mathrm{P}=0.000 ; 1$ week: $\mathrm{r}=0.630, \mathrm{P}=0.001 ; 1$ month: $r=0.667, P=0.000$ (Figure $2 A$ )], negatively correlated with eGFR [ 1 day: $r=-0.557$, $\mathrm{P}=0.005$; 1 week: $\mathrm{r}=-0.483, \mathrm{P}=0.017 ; 1$ month: $\mathrm{r}=0.667, \mathrm{P}=0.000$ (Figure 2B)], positively correlated with serum pre-albumin $[1$ day: $\mathrm{r}=0.172, \mathrm{P}=0.422 ; 1$ week: $\mathrm{r}=0.279, \mathrm{P}=0.186 ; 1$ month: $\mathrm{r}=0.432, \mathrm{P}=0.035$ (Figure $2 \mathrm{C}$ )], and positively correlated with serum blood urea nitrogen $[1$ day: $\mathrm{r}=0.316, \mathrm{P}=0.132 ; 1$ week: $\mathrm{r}=0.650, \mathrm{P}=0.001 ; 1$ month: $\mathrm{r}=0.567, \mathrm{P}=0.000$ (Figure 2D)].

Table 1 also shows clinical parameters selected. Before kidney transplantation, blood urea nitrogen and serum phosphate were significantly higher, while serum total bilirubin and direct bilirubin were significantly lower in ESRD patients compared with control subjects (Table 1). Blood urea nitrogen and serum phosphate decreased, whereas serum total and direct bilirubin increased significantly at all 3 time points after kidney transplantation (Table 1). In addition, the percent change in phosphate concentration was positively correlated with that of serum RBP4 at 1 month after transplantation $(\mathrm{r}=0.432, \mathrm{P}=0.000)$. The percent change of other studied parameters, such as serum alanine aminotransferase and aspartate aminotransferase activity, serum total, and direct bilirubin, were not significantly correlated with serum 
Level of RBP4 in patients after kidney transplantation

A

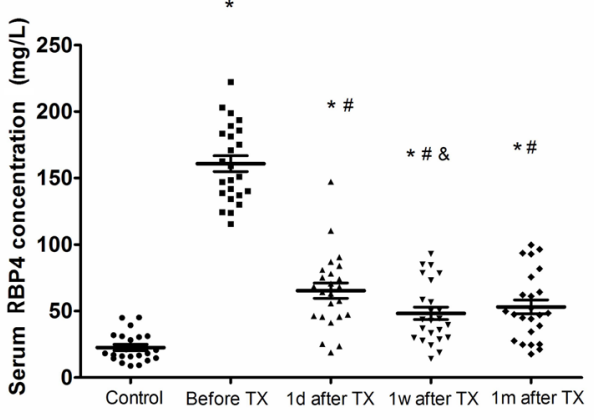

B

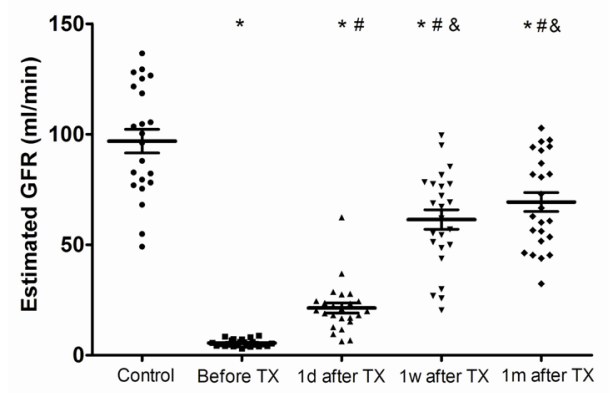

C

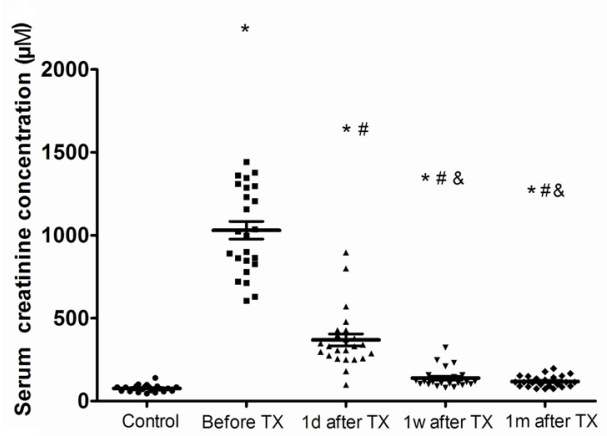

D

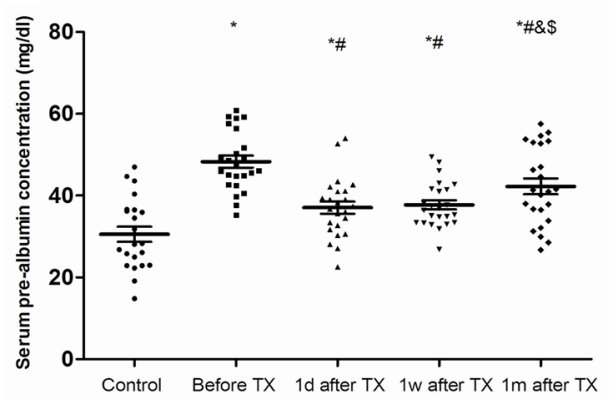

Figure 1. A. Serum RBP4 concentration, B. estimated glomerular filtration rate, C. serum creatinine concentration, D. serum pre-albumin concentration in control subjects and patients with end-stage renal disease before transplantation and 1 day, 1 week, and 1 month after transplantation. Results for individuals are shown as closed markers. The mean values are illustrated as a line, and the standard deviations are illustrated by the error bar. *Compared with control subjects, $\mathrm{P}<0.05$; " compared with that before transplantation, $\mathrm{P}<0.05$; and compared with that 1 day after transplantation, $\mathrm{P}<0.05$. 
A

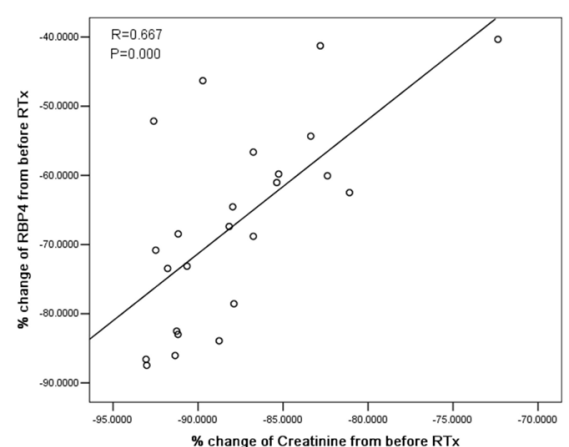

B

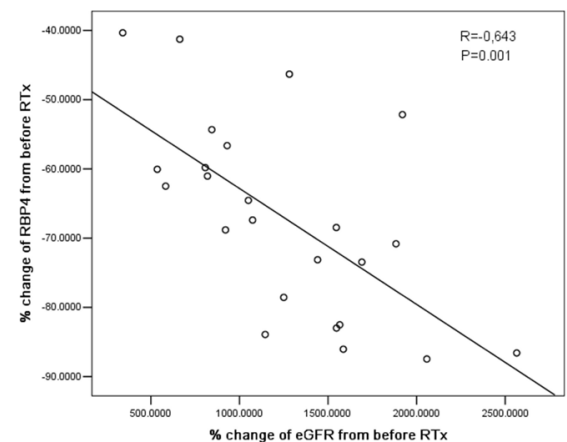

C

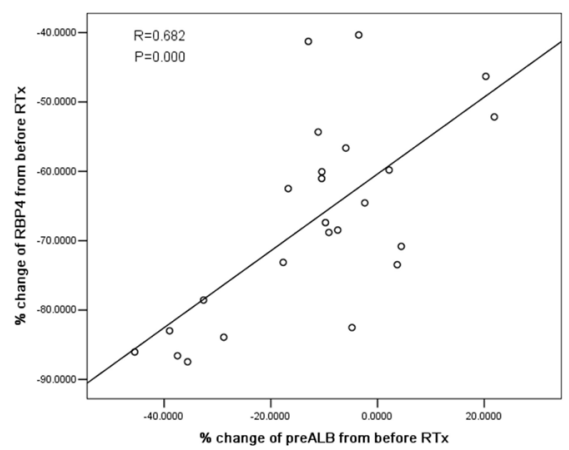

D

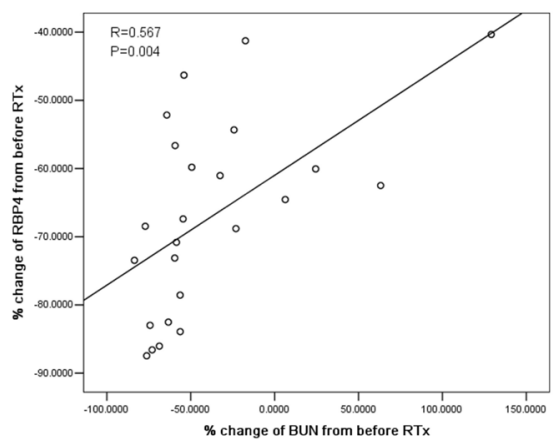

Figure 2. Correlation of $\%$ change from before kidney transplantation of serum RBP4 concentrations with that serum creatinine (A), eGFR (B), pre-albumin (C), and blood urea nitrogen (D) at 1 month after kidney transplantation. 
RBP4 before and after kidney transplantation.

\section{DISCUSSION}

The most important finding of this study was that elevated serum RBP4 in patients with ESRD significantly decreased after kidney transplantation (Figure 1A). Changes in serum RBP4 were negatively correlated with changes in eGFR, as well as positively correlated with changes in serum creatinine. These results suggest that serum RBP4 is associated with renal function.

The most probable cause of increased serum RBP4 concentration in ESRD patients was insufficient renal elimination of serum RBP4 because of insufficient renal filtration and/ or renal degradation (Mogielnicki et al., 1971; Smith and Goodman, 1971; Goodman, 1984). Therefore, successful kidney transplantation may result in decreased RBP4 elimination by the transplanted kidney. This hypothesis was supported by our results and by those of Kelleher et al. (1983). However, Frey et al. (2009) investigated serum levels of RBP4 and its isoforms in 18 hemodialysis patients, 30 kidney transplant recipients, and 35 healthy controls. Their results were consistent with ours, showing that RBP4 was elevated in both hemodialysis patients and kidney transplant recipients. Surprisingly, in their study, kidney transplant recipients showed higher RBP4 levels than hemodialysis patients, which is in contrast with our results. This discrepancy may have been caused by 2 factors. First, Frey et al. (2009) did not compare serum RBP4 levels of the same patient before and after kidney transplantation. Second, eGFR levels in their kidney transplant recipients were lower than those in our patients after kidney transplantation (mean value $24.75 \mathrm{~mL} / \mathrm{min}$ vs $69.33 \mathrm{~mL} / \mathrm{min}$ ).

Increased serum RBP4 levels are reportedly associated with body mass index, waist circumference, and insulin resistance (Yang et al., 2005; Graham et al., 2006; Cabré et al., 2007). We observed that serum RBP4 concentrations decreased rapidly as early as 1 day after kidney transplantation. This decrease in serum RBP4 level was likely not caused by any change in body mass index, waist circumference, and insulin resistance because of the relatively short time following transplantation. Patients with chronic liver diseases have significantly decreased RBP4 serum concentrations, and serum RBP4 has been directly linked to liver function in these patients (Yagmur et al., 2007). In the present study, all patients were free of chronic liver diseases and their liver function indices remained within the normal range throughout the observation period, indicating that the change in serum RBP4 concentration was unaffected by changes in liver function.

Some limitations of the present study should be noted. First, the study included a relatively small sample size. However, this limitation was counterbalanced by the ability to compare serum RBP4 concentrations of the same individuals before and after kidney transplantation. Second, we did not determine urine RBP4 concentrations. Further studies, including urine RBP4 concentration analysis, are required to resolve whether renal RBP4 elimination affects serum RBP4 concentration in patients with ESRD before and after kidney transplantation.

In summary, we showed that successful kidney transplantation significantly decreases elevated serum RBP4 concentrations in patients with ESRD. Therefore, renal filtration and renal degradation likely affects the elimination of serum RBP4.

\section{REFERENCES}

Adoncecchi L, Marrocco W, Suraci C, Pecora P, et al. (1984). Effect of renal and liver failure on blood levels of vitamin A, its precursor (beta-carotene) and its carrier proteins (prealbumin and retinol binding protein). Boll. Soc. Ital. Biol. 
Sper. 60: 881-886.

Bernard A, Vyskocyl A, Mahieu P and Lauwerys R (1988). Effect of renal insufficiency on the concentration of free retinol-binding protein in urine and serum. Clin. Chim. Acta 171: 85-93.

Blaner WS (1989). Retinol-binding protein: the serum transport protein for vitamin A. Endocr. Rev. 10: 308-316.

Blumberg A, Hanck A and Sander G (1983). Vitamin nutrition in patients on continuous ambulatory peritoneal dialysis (CAPD). Clin. Nephrol. 20: 244-250.

Cabré A, Lázaro I, Girona J, Manzanares J, et al. (2007). Retinol-binding protein 4 as a plasma biomarker of renal dysfunction and cardiovascular disease in type 2 diabetes. J. Intern. Med. 262: 496-503.

Farrington K, Miller P, Varghese Z, Baillod RA, et al. (1981). Vitamin A toxicity and hypercalcaemia in chronic renal failure. Br. Med. J. (Clin. Res. Ed.) 282: 1999-2002.

Frey SK, Henze A, Nagl B, Raila J, et al. (2009). Effect of renal replacement therapy on retinol-binding protein 4 isoforms. Clin. Chim. Acta 401: 46-50.

Goodman DS (1980). Plasma retinol-binding protein. Ann. N. Y. Acad. Sci. 348: 378-390.

Goodman DS (1984). Plasma Retinol-Binding Protein. In: The Retinoids. Vol. 2. (Sporn MB, Roberts AB and Goodman DS, eds.). Academic Press, Orlando, 41-88.

Graham TE, Yang Q, Blüher M, Hammarstedt A, et al. (2006). Retinol-binding protein 4 and insulin resistance in lean, obese, and diabetic subjects. N. Engl. J. Med. 354: 2552-2563.

Jaconi S, Rose K, Hughes GJ, Saurat JH, et al. (1995). Characterization of two post-translationally processed forms of human serum retinol-binding protein: altered ratios in chronic renal failure. J. Lipid Res. 36: 1247-1253.

Janke J, Engeli S, Boschmann M, Adams F, et al. (2006). Retinol-binding protein 4 in human obesity. Diabetes 55: 28052810.

Kelleher J, Humphrey CS, Homer D, Davison AM, et al. (1983). Vitamin A and its transport proteins in patients with chronic renal failure receiving maintenance haemodialysis and after renal transplantation. Clin. Sci. 65: 619-626.

Kiernan UA, Tubbs KA, Nedelkov D, Niederkofler EE, et al. (2002). Comparative phenotypic analyses of human plasma and urinary retinol binding protein using mass spectrometric immunoassay. Biochem. Biophys. Res. Commun. 297: 401-405.

Levey AS, Greene T, Kusek JW and Beck GJ (2000). A simplified equation to predict glomerular filtration rate from serum creatinine. J. Am. Soc. Nephrol. 11: 0828.

Mogielnicki RP, Waldmann TA and Strober W (1971). Renal handling of low molecular weight proteins. I. L-Chain metabolism in experimental renal disease. J. Clin. Invest. 50: 901-909.

Naylor HM and Newcomer ME (1999). The structure of human retinol-binding protein (RBP) with its carrier protein transthyretin reveals an interaction with the carboxy terminus of RBP. Biochemistry 38: 2647-2653.

Peterson PA and Berggard I (1971). Isolation and properties of a human retinol-transporting protein. J. Biol. Chem. 246: 25-33.

Raila J, Willnow TE and Schweigert FJ (2005). Megalin-mediated reuptake of retinol in the kidneys of mice is essential for vitamin A homeostasis. J. Nutr. 135: 2512-2516.

Ronne H, Ocklind C, Wiman K, Rask L, et al. (1983). Ligand-dependent regulation of intracellular protein transport: effect of vitamin a on the secretion of the retinol-binding protein. J. Cell Biol. 96: 907-910.

Smith FR and Goodman DS (1971). The effects of diseases of the liver, thyroid, and kidneys on the transport of vitamin A in human plasma. J. Clin. Invest. 50: 2426-2436.

Stewart WK and Fleming LW (1982). Plasma retinol and retinol binding protein concentrations in patients on maintenance haemodialysis with and without vitamin A supplements. Nephron 30: 15-21.

Vahlquist A, Peterson PA and Wibell L (1973). Metabolism of the viatmin A transporting protein complex. I. Turnover studies in normal persons and in patients with chronic renal failure. Eur. J. Clin. Invest. 3: 352-362.

Vahlquist A, Berne B and Berne C (1982). Skin content and plasma transport of vitamin A and beta-carotene in chronic renal failure. Eur. J. Clin. Invest. 12: 63-67.

Wihler C, Schafer S, Schmid K, Deemer EK, et al. (2005). Renal accumulation and clearance of advanced glycation end-products in type 2 diabetic nephropathy: effect of angiotensin-converting enzyme and vasopeptidase inhibition. Diabetologia 48: 1645-1653.

Yagmur E, Weiskirchen R, Gressner AM, Trautwein C, et al. (2007). Insulin resistance in liver cirrhosis is not associated with circulating retinol-binding protein 4. Diabetes Care 30: 1168-1172.

Yang Q, Graham TE, Mody N, Preitner F, et al. (2005). Serum retinol binding protein 4 contributes to insulin resistance in obesity and type 2 diabetes. Nature 436: 356-362.

Ziegelmeier M, Bachmann A, Seeger J, Lossner U, et al. (2007). Serum levels of adipokine retinol-binding protein-4 in relation to renal function. Diabetes Care 30: 2588-2592. 